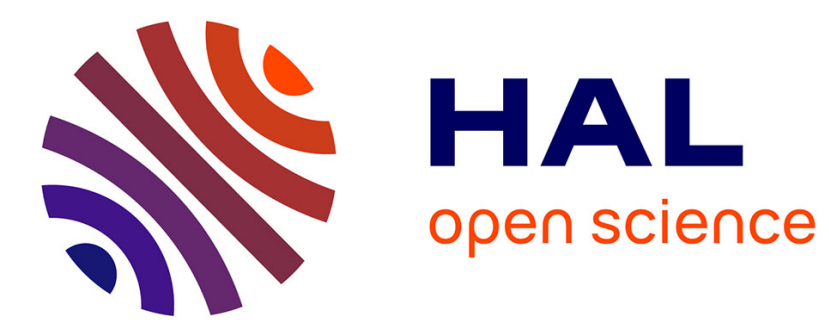

\title{
High Temperature Fatigue of SPF Die Ni-Cr-Fe Heat Resistant Nickel-Chromium Cast Steels
}

Vincent Velay, Gérard Bernhart, A. Martinier, J-Y. Moraux

\section{To cite this version:}

Vincent Velay, Gérard Bernhart, A. Martinier, J-Y. Moraux. High Temperature Fatigue of SPF Die Ni-Cr-Fe Heat Resistant Nickel-Chromium Cast Steels. ICSAM 2009 - 10th International Conference on Superplasticity in Advanced Materials, Jun 2009, Seattle, United States. pp.69+, 10.4028/www.scientific.net/KEM.433.69 . hal-01703243

\section{HAL Id: hal-01703243 \\ https://hal.science/hal-01703243}

Submitted on 10 Feb 2020

HAL is a multi-disciplinary open access archive for the deposit and dissemination of scientific research documents, whether they are published or not. The documents may come from teaching and research institutions in France or abroad, or from public or private research centers.
L'archive ouverte pluridisciplinaire HAL, est destinée au dépôt et à la diffusion de documents scientifiques de niveau recherche, publiés ou non, émanant des établissements d'enseignement et de recherche français ou étrangers, des laboratoires publics ou privés. 


\title{
High Temperature Fatigue of SPF Die Ni-Cr-Fe Heat Resistant Nickel- Chromium Cast Steels
}

\author{
V. Velay ${ }^{1,2, a}$, G. Bernhart ${ }^{1,2, b}$, A. Martinier ${ }^{2, a}$ and J-Y. Moraux ${ }^{3, c}$ \\ ${ }^{1}$ Université de Toulouse; INSA, UPS, Mines Albi, ISAE; ICA (Institut Clément Ader), CROMeP; \\ Campus Jarlard, F-81013 Albi cedex 09, France \\ ${ }^{2}$ Ecole des Mines Albi, Centre CROMeP, Campus jarlard, F-81013 Albi, France \\ Eramet Aubert \&Duval, Foundry Division, 63770 Les ANCIZES, France
}

avincent.velay@mines-albi.fr, bgerard.bernhart@mines-albi.fr, cjean-yves.moraux@erametaubertduval.com

Keywords: High Temperature Fatigue, SPF Die, Ni-Cr-Fe Heat Resistant Nickel-Chromium Cast Steels.

\begin{abstract}
Superplastic forming of titanium alloy sheets requests long time operating conditions in the range of $900-950^{\circ} \mathrm{C}$. Moreover, in a classical press-furnace process environment, die surface temperature drops during sheet unloading and induces high temperature thermo-mechanical fatigue. In order to withstand such extreme conditions in oxidative atmosphere, cast heat resistant nickel chromium steel grades have been developed. The high chromium content (close to $25 \%$ ) aims to protect against the oxidizing environment, whereas the nickel content is selected with respect to the expected in service loads. The 50\% nickel grades are in general used for heating plates, huge casings and cover-plates; whereas $40 \%$ nickel grades are selected for inserts and medium size selfstanding dies. Cost considerations (Nickel and machining) are also taken into account by the end users for making their choice. An extensive testing program has been performed, in the range of 20 to $950^{\circ} \mathrm{C}$, to understand the high temperature fatigue behaviour of these grades and to identify material behaviour models for simulation purposes. This paper presents the major results of these research works and highlights the impact of the nickel content in terms of stress level and life time. Nevertheless, when looking on behaviour, test results show that a unified elasto-visco-plastic cyclic behaviour model is well suited for thermo-mechanical cyclic modelling whatever the grade is. Isothermal identification strategy and out of phase SPF die representative anisothermal fatigue validation are presented.
\end{abstract}

\section{Introduction}

Heat resistant cast steels are currently used to manufacture SPF tools [1]. They allow forming superplastic titanium based sheets. During a production campaign, the tools undergo very high thermo-mechanical cyclic loadings due to the SPF operations. The moulding is carried out at a maximal temperature close to $900^{\circ} \mathrm{C}$ (inside the heating press) and a minimal temperature depending on the locations at the surface of the die close to $200^{\circ} \mathrm{C}$, when the mould is pulled out from the heating press to form a new part [2]. These thermal cyclic conditions are repeated as many times as necessary to produce the required number of parts. They induce mechanical stresses and cyclic plasticity that may lead to the failure of the die. In order to increase the tool lifetime, numerical simulation can be an efficient approach to assess the cyclic plasticity in the dies and to improve the tool design [3]. But it requires the implementation of accurate behaviour models associated with lifetime criterion [4,5]. In this paper, behaviour and lifetime investigations were performed on GX30NiCr39-24 and GX45NiCr49-27 materials commonly used to manufacture SPF dies. After a microstructural analysis, an experimental program is conducted in order to investigate the cyclic behaviour of the materials. It takes into account the cyclic hardening, the strain rate and dwell time effects very significant at high temperatures. Afterwards, a phenomenological model is presented and identified from the previous tests in order to describe the thermo-mechanical stress- 
strain hysteresis loops of both materials. Then, the approach is validated by comparison of the model response with several thermo-mechanical fatigue tests. Lastly, a complete fatigue lifetime investigation performed on $\mathrm{GX} 30 \mathrm{NiCr} 39-24$ grade is presented.

\section{Materials and fatigue behaviour}

Two heat-resistant cast austenitic stainless steels, widely used in SPF tooling, are investigated, referred to as GX30NiCr39-24 and GX45NiCr49-27 (Eramet Aubert \& Duval commercial grades $\mathrm{XN40TF}$ and XN50TF). The chemical composition of both materials is presented in Table 1. These alloys have similar $\mathrm{Cr}$ content and differ in their content in other alloying elements. GX30NiCr3924 contains less carbon than GX45NiCr49-27, which exhibits $5 \mathrm{wt} \%$ tungsten, enhancing the volume fraction of $\mathrm{W}$ carbides. The microstructure of these alloys consists of a typical denditric structure (Fig. 1a), with coarse primary arms, separated carbide rich interdenditric zones. The centre of the dendrites reveals also the presence of secondary carbides (Fig. 1b), precipitated during the ageing treatment carried out after casting [6]. This stabilisation treatment consists in 24 hours exposure to $950^{\circ} \mathrm{C}$ and promotes the carbide precipitation in excess of the solid solution.

\begin{tabular}{|c|c|c|c|c|c|c|c|c|c|c|c|}
\hline Grades & Fe & $\mathrm{C}$ & $\mathrm{Si}$ & $\mathrm{Mn}$ & $\mathrm{S}$ & $\mathrm{P}$ & $\mathrm{Ni}$ & $\mathrm{Cr}$ & $\mathrm{Mo}$ & $\mathrm{W}$ & $\mathrm{Nb}$ \\
\hline GX30NiCr39-24 & Bal. & 0.31 & 1.45 & 1.11 & 0.0011 & $<0.001$ & 39.2 & 24.4 & $<0.02$ & $<0.002$ & 0.328 \\
\hline GX45NiCr49-27 & Bal. & 0.46 & 1.21 & 0.98 & 0.001 & 0.01 & 49 & 26.76 & & 4.95 & \\
\hline
\end{tabular}

Table 1: Chemical composition (wt. \%) of the investigated steels (Eramet Aubert \& Duval grades)

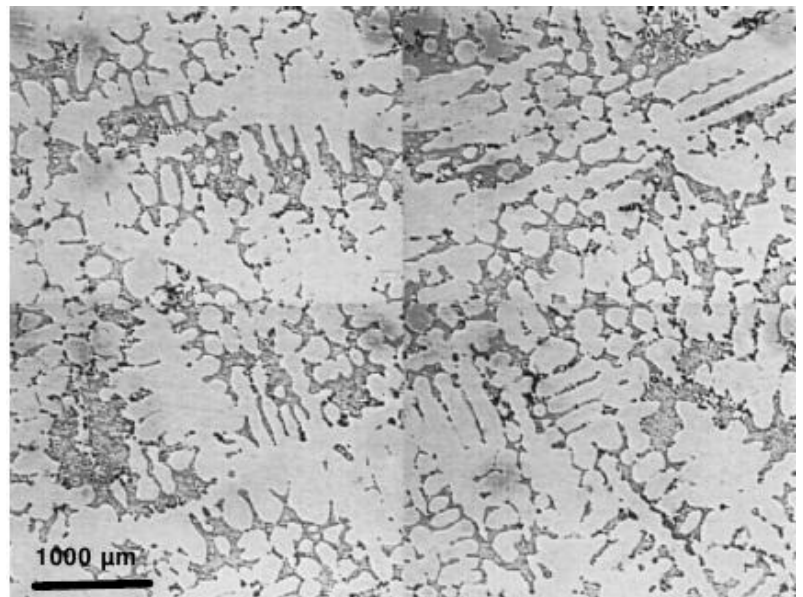

(a)

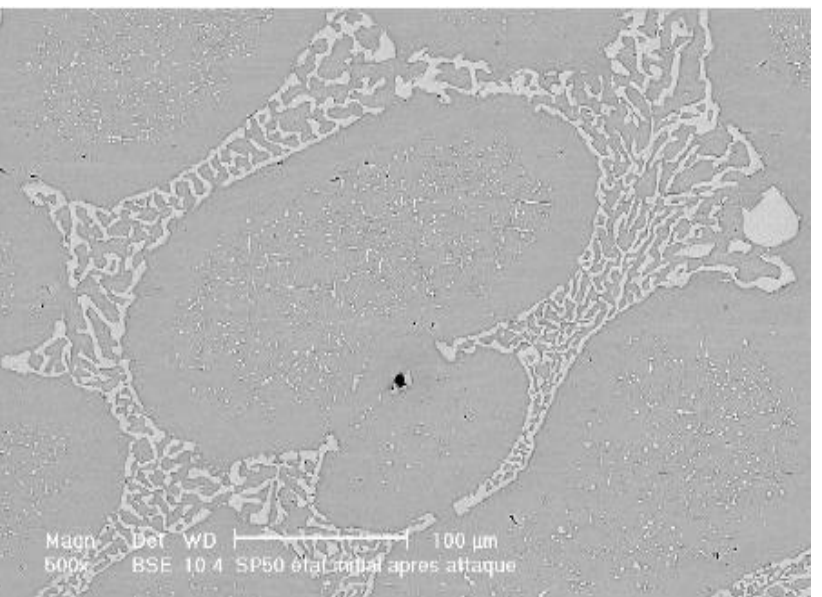

(b)

Fig. 1: Microstructure of the GX45NiCr49-27 material (a) Typical dendritric structure (b) Primary and secondary carbides

Low cycle fatigue tests were carried out with a MTS servo-hydraulic testing machine and testar II $^{\mathrm{TM}}$ controller connected to a computer. Heating was achieved with an induction coil. Symmetrical isothermal strain controlled fatigue tests between $500^{\circ} \mathrm{C}$ and $950^{\circ} \mathrm{C}$ were performed with a constant total strain range of $1.2 \%$ and a constant strain rate of $10^{-3} \mathrm{~s}^{-1}$. Both materials are characterized by a slight cyclic hardening at low temperatures that vanishes at high temperatures $\left(\mathrm{T}>800^{\circ} \mathrm{C}\right)$. Figure 2 illustrates the stress amplitude versus the number of cycles for different levels of temperatures, for both materials. If similar trends were observed for both grades, the higher the Nickel content is, the higher the stress levels are. Moreover, the influence of strain rate on the material behaviour was investigated. This effect, very important at high temperatures (Fig. 3a for GX45NiCr49-27), becomes negligible for the lowest temperatures. It is characterized by a decrease of the stress amplitude with the strain rate. Last, an important stress relaxation was noticed for cycles including tensile dwell time. As previously, this temperature-dependent effect can induce a significant increase of the cyclic plasticity (see Fig. $3 b$ for GX30NiCr39-24 material). 


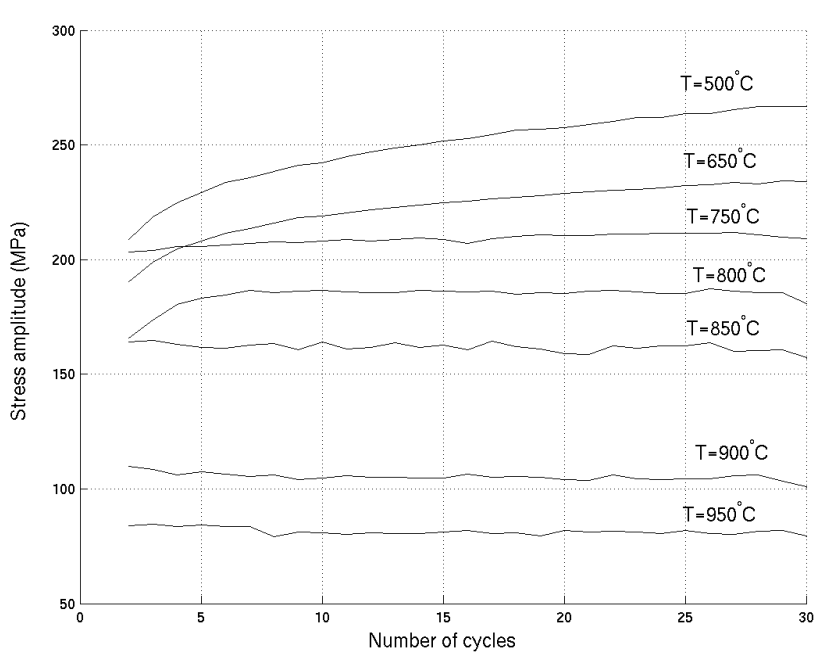

(a)

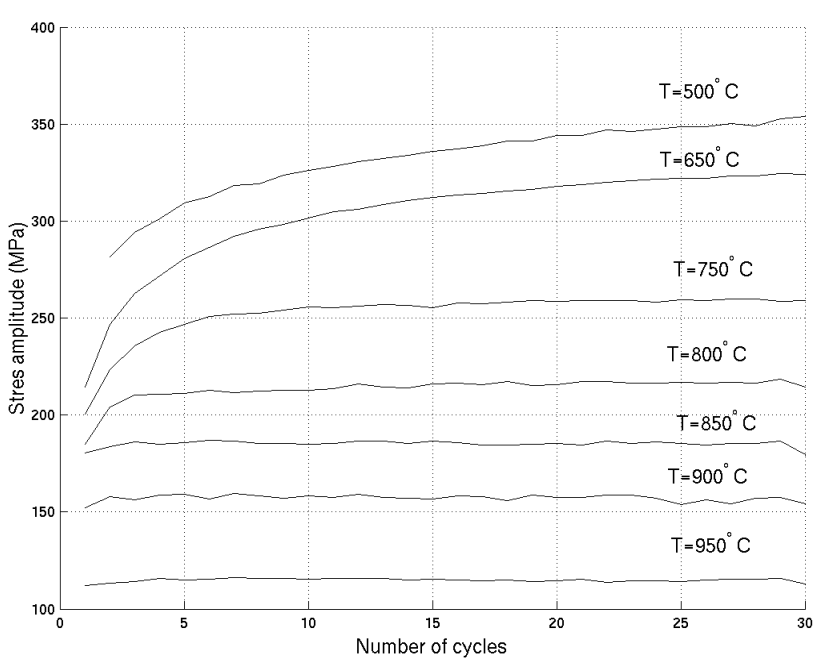

(b)

Fig. 2: Typical cyclic behaviour of the (a) GX30NiCr39-24 and (b) GX45NiCr49-27 materials

\section{Behaviour Modelling of GX30NiCr39-24 and GX45NiCr49-27 Steels}

Model Formation and Identification Methodology. The general fatigue experimental procedure has been widely detailed in several previous works as [7]. The methodology allows identifying the constitutive behaviour model. For each test temperature $\left(500^{\circ} \mathrm{C}\right.$ to $\left.950^{\circ} \mathrm{C}\right)$, it only required one material sample. The fatigue test includes two different stages. The first one consists in a number of cycles so as to reach a stabilised strain-stress response of the material at a constant strain rate of $10^{-3} \mathrm{~s}^{-1}$ (see Fig. 2). Afterwards, the strain rate is varied from $10^{-3} \mathrm{~s}^{-1}$ to $10^{-5} \mathrm{~s}^{-1}$ and three cycles are performed at each strain rate in order to obtain a stabilised cycle (see Fig. 3a). Last, fatigue relaxation cycles are included with a strain rate of $10^{-3} \mathrm{~s}^{-1}$ with a dwell time of $600 \mathrm{~s}$.

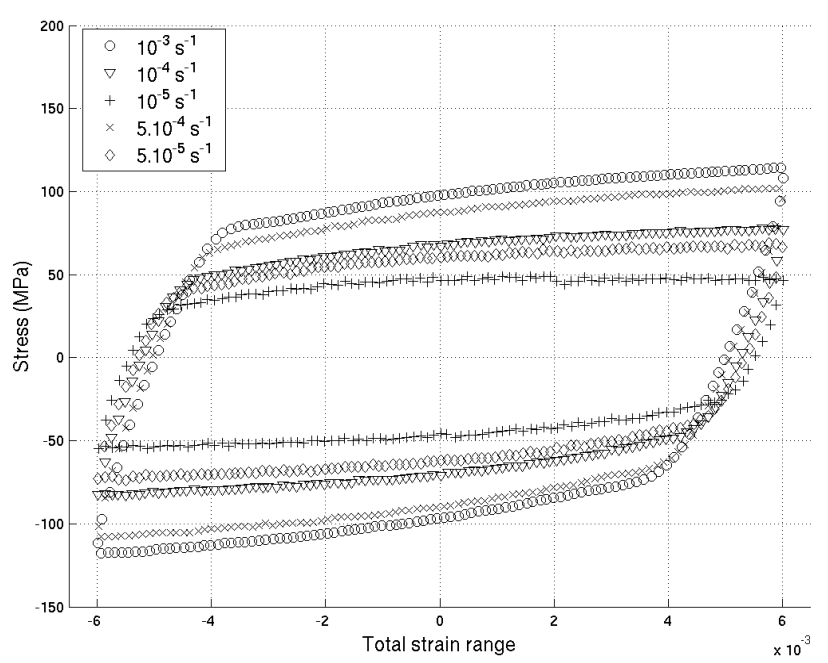

(a)

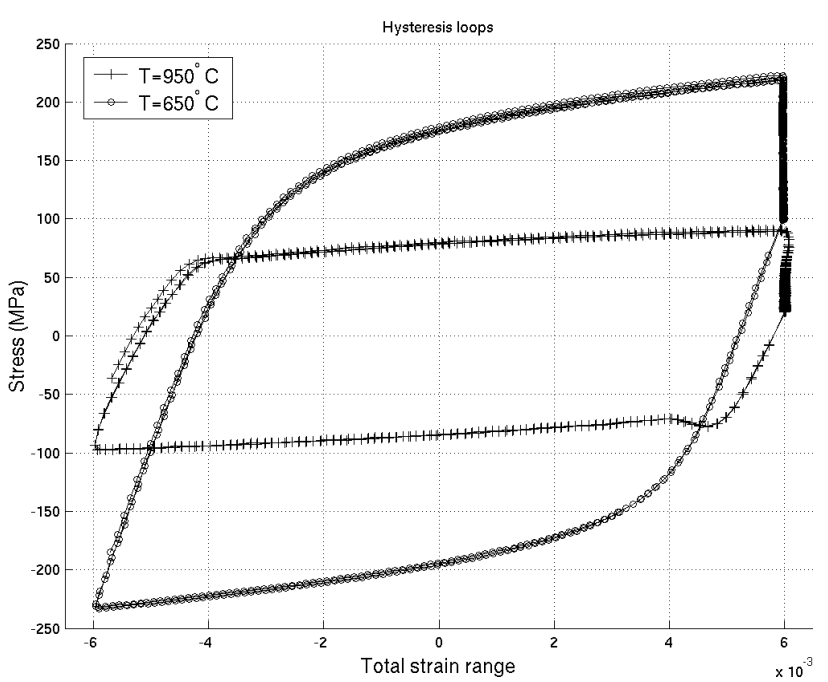

(b)

Fig. 3: (a) Strain rate effect at $950^{\circ} \mathrm{C}$ observed on the GX45NiCr49-27 material (b) Stress relaxation effect observed on the material at $\mathrm{T}=650^{\circ} \mathrm{C}$ and $\mathrm{T}=950^{\circ} \mathrm{C}(600$ s relaxation)

The behaviour model is based on several constitutive equations formulated within the theoretical framework of the thermodynamics of the irreversible processes [8]. In the next, the nomenclature $\underline{\sigma}$ will be used to describe the two order stress tensor. The same nomenclature will be considered for any two order tensor. A unified approach is considered with the partition of total strain into an elastic and viscoplastic parts:

$$
\underline{\mathcal{E}_{t}}=\underline{\mathcal{E}_{e}}+\underline{\mathcal{E}_{v p}} .
$$


The model is defined through two kinds of variables: the state and the evolution variables. The first one is derived from the free energy potential, and provides a relationship between associated and evolution variables. In our case, two kinematic components $\underline{X}=\underline{X_{1}}+\underline{X_{2}}$ are considered to describe the fast evolution for one cycle, like the baushinger effect. The isotropic component is assumed to be constant $R=R_{0}$. The state laws can be written as:

$$
\underline{\sigma}=\underline{\underline{C}} \underline{\varepsilon_{e}}, \quad \underline{X_{i}}=\frac{2}{3} C_{i} \underline{\alpha_{i}} .
$$

$\underline{\underline{C}}$ is the fourth order Hooke's tensor, $C_{i}$ is a scalar model parameter depending on temperature, and $\alpha_{i}$ corresponds to an internal variable.

The evolution equations are provided by the viscoplastic dissipation potential, considering a vonMises type yield surface:

$$
f=J(\underline{\sigma}-\underline{X})-R_{0}
$$

with $J(\underline{\sigma}-\underline{X})=\sqrt{\frac{3}{2}\left(\underline{\sigma}-\underline{X^{\prime}}\right):\left(\underline{\sigma}-\underline{X^{\prime}}\right)}$, where $\underline{X}^{\prime}$ and $\underline{\sigma}^{\prime}$ correspond to the deviatoric parts of $\underline{X}$ and $\underline{\sigma} . R_{0}$ defines the elastic limit of the material.

The evolution equations include viscoplastic strain evolution and the flow rules of internal variable (back stress $\underline{X}$ ); they are written as follows:

$$
\dot{\mathcal{\varepsilon}}_{v p}=\frac{3}{2} \dot{p} \frac{\stackrel{\sigma}{\sigma}-\underline{X}^{\prime}}{J(\underline{\sigma}-\underline{X})}, \quad \dot{p}=\left\langle\frac{f}{K}\right\rangle^{n}, \quad \dot{\alpha}=\underline{\dot{\mathcal{E}}_{v p}}-D_{i} \underline{\alpha_{i}} \dot{p} .
$$

where $p$ is the cumulative plastic strain, $K$ and $n$ correspond to the viscous parameters, and $D_{i}$ belongs to the dynamic recovery term of the back stress component.

For one dimensional test condition, the stress and the viscoplastic tensors can be written as:

$$
\underline{\sigma}=\left(\begin{array}{ccc}
\sigma & 0 & 0 \\
0 & 0 & 0 \\
0 & 0 & 0
\end{array}\right), \quad \underline{X_{i}}=\left(\begin{array}{ccc}
\frac{2}{3} X_{i} & 0 & 0 \\
0 & -\frac{1}{3} X_{i} & 0 \\
0 & 0 & -\frac{1}{3} X_{i}
\end{array}\right), \quad \underline{\boldsymbol{\varepsilon}_{v p}}=\left(\begin{array}{ccc}
\mathcal{E}_{v p} & 0 & 0 \\
0 & -\frac{1}{2} \varepsilon_{v p} & 0 \\
0 & 0 & -\frac{1}{2} \varepsilon_{v p}
\end{array}\right)
$$

Hence, the model formulation is reduced as the following form:

- $\quad$ yield criterion: $f=|\sigma-X|-R_{0}$;

- $\quad$ state laws: $\sigma=E \varepsilon_{e} ; \quad X_{i}=C_{i} \alpha_{i}$;

- $\quad$ evolution equations: $\dot{\mathcal{E}}_{v p}=\dot{p} \operatorname{sign}(\sigma-X) ; \quad \dot{p}=\left\langle\frac{f}{K}\right\rangle^{n} ; \quad \dot{\alpha}_{i}=\dot{\mathcal{E}}_{v p}-D_{i} \alpha_{i} \dot{p}$;

with $\langle f\rangle=f . H(f)$, and $\mathrm{H}$ is defined as the Heaviside function.

The elastic behaviour has been investigated for each sample. At the beginning of the fatigue test, the Young modulus is measured at room temperature $\left(\mathrm{T}=25^{\circ} \mathrm{C}\right)$ for a pre-loading of $50 \mathrm{MPa}$. Afterwards, the cycles are performed at the required temperature level. The elastic modulus values show a significant and unusual discrepancy, mainly due to a basaltic grain size close to the gauge length. For this reason, the ratio $\mathrm{E}_{\mathrm{T}} / \mathrm{E}_{25}$ is considered. Table 2 and 3 provide the correlation between the values of the elastic modulus measured before cycling $\left(\mathrm{T}=25^{\circ} \mathrm{C}\right)$ and those measured at the test temperature for both materials. Table 4 gives the values of the model parameters for the 
GX45NiCr49-27 steel. Constant values have been considered for the dynamic recovery terms related to the kinematic component, $\mathrm{D}_{1}=3000$ and $\mathrm{D}_{2}=300$. Last, Fig. 4 illustrates the model capability to describe the strain-stress response and to take into account the strain rate effect activated at high temperature. Additional results can be found in [9].

\begin{tabular}{|c|c|c|c|c|c|c|c|c|c|}
\hline $\mathrm{T}\left[{ }^{\circ} \mathrm{C}\right]$ & 25 & 350 & 500 & 650 & 750 & 800 & 850 & 900 & 950 \\
\hline $\mathrm{E}_{25}[\mathrm{GPa}]$ & 229.5 & 226.1 & 180.3 & 171 & 196.1 & 181.4 & 213 & 160.1 & 163.7 \\
\hline $\mathrm{E}_{\mathrm{T}}[\mathrm{GPa}]$ & 216.3 & 180 & 140 & 131.1 & 146.1 & 118.4 & 129.4 & 95.5 & 95.6 \\
\hline $\mathrm{E}_{\mathrm{T}} / \mathrm{E}_{25}$ & 0.94 & 0.8 & 0.78 & 0.77 & 0.75 & 0.65 & 0.61 & 0.6 & 0.58 \\
\hline
\end{tabular}

Table 2: Elastic modulus values measured before cycling $\left(\mathrm{T}=25^{\circ} \mathrm{C}\right)$ and at the test temperature for the GX30NiCr39-24 steel

\begin{tabular}{|c|c|c|c|c|c|c|c|}
\hline $\mathrm{T}\left[{ }^{\circ} \mathrm{C}\right]$ & 500 & 650 & 750 & 800 & 850 & 900 & 950 \\
\hline $\mathrm{E}_{25}[\mathrm{GPa}]$ & 191 & 153.5 & 169.2 & 176.6 & 185.1 & 214.1 & 176.5 \\
\hline $\mathrm{E}_{\mathrm{T}}[\mathrm{GPa}]$ & 174.5 & 121.6 & 126.1 & 130.9 & 129.1 & 144.6 & 87.8 \\
\hline $\mathrm{E}_{\mathrm{T}} / \mathrm{E}_{25}$ & 0.91 & 0.77 & 0.75 & 0.74 & 0.7 & 0.68 & 0.50 \\
\hline
\end{tabular}

Table 3: Elastic modulus values measured before cycling $\left(\mathrm{T}=25^{\circ} \mathrm{C}\right)$ and at the test temperature for the GX45NiCr49-27 steel

\begin{tabular}{|c|c|c|c|c|c|}
\hline $\mathrm{T}\left[{ }^{\circ} \mathrm{C}\right]$ & $\mathrm{R}_{0}[\mathrm{MPa}]$ & $\mathrm{K}\left[{\left.\mathrm{MPa} . \mathrm{s}^{1 / \mathrm{n}}\right]}\right.$ & $\mathrm{n}$ & $\mathrm{C}_{1}[\mathrm{MPa}]$ & $\mathrm{C}_{2}[\mathrm{MPa}]$ \\
\hline 500 & 29 & 68.5 & 12 & 320000 & 54501 \\
\hline 650 & 13 & 213.5 & 10 & 357715 & 36799 \\
\hline 750 & 0 & 518 & 6.3 & 80539 & 21586 \\
\hline 800 & 0 & 605 & 5 & 63966 & 15900 \\
\hline 850 & 0 & 530 & 5 & 37834 & 13059 \\
\hline 900 & 0 & 486 & 5 & 23741 & 9037 \\
\hline 950 & 0 & 377 & 5 & 4281 & 4472 \\
\hline
\end{tabular}

Table 4: Temperature-dependent model parameters for the GX45NiCr49-27 steel

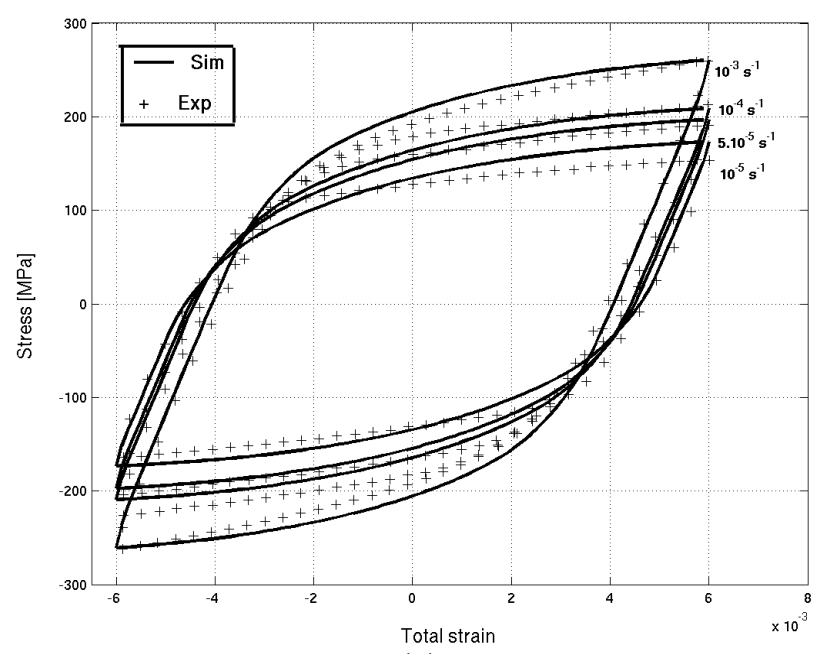

(a)

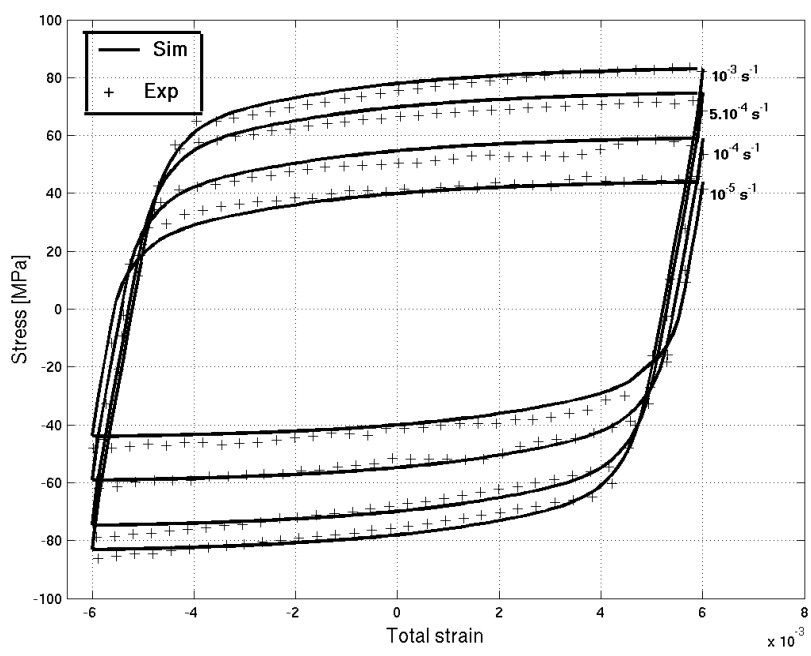

(b)

Fig. 4: Comparison between experimental and simulated loops at different strain rates for the (a) $\mathrm{GX} 45 \mathrm{NiCr} 49-27$ material at $\mathrm{T}=750^{\circ} \mathrm{C}$ (b) $\mathrm{GX} 45 \mathrm{NiCr} 49-24$ material at $\mathrm{T}=950^{\circ} \mathrm{C}$ 
Non-Isothermal Validation. The test conditions have been carefully selected in order to cover the typical loads expected on SPF dies. They consider thermo-mechanical cycles including dwell times with different temperature ranges and a positive mechanical strain (see Fig. 5). Several kinds of cycles have been defined.

Cycle 1 considers out of phase cycles with temperature amplitude between 500 and $950{ }^{\circ} \mathrm{C}$, and a mechanical strain range varying from $0.8 \%$ to $1.4 \%$, depending on the material. Cycle 2 includes out of phase cycles as previously, but with reduced temperature amplitude between 750 and $900^{\circ} \mathrm{C}$. Cycle 3 is also performed in out of phase conditions, with a tensile dwell time of 2 or 3 minutes. Last, cycle 4 is similar to cycle 1 , but with a larger temperature range between 350 and $950^{\circ} \mathrm{C}$.

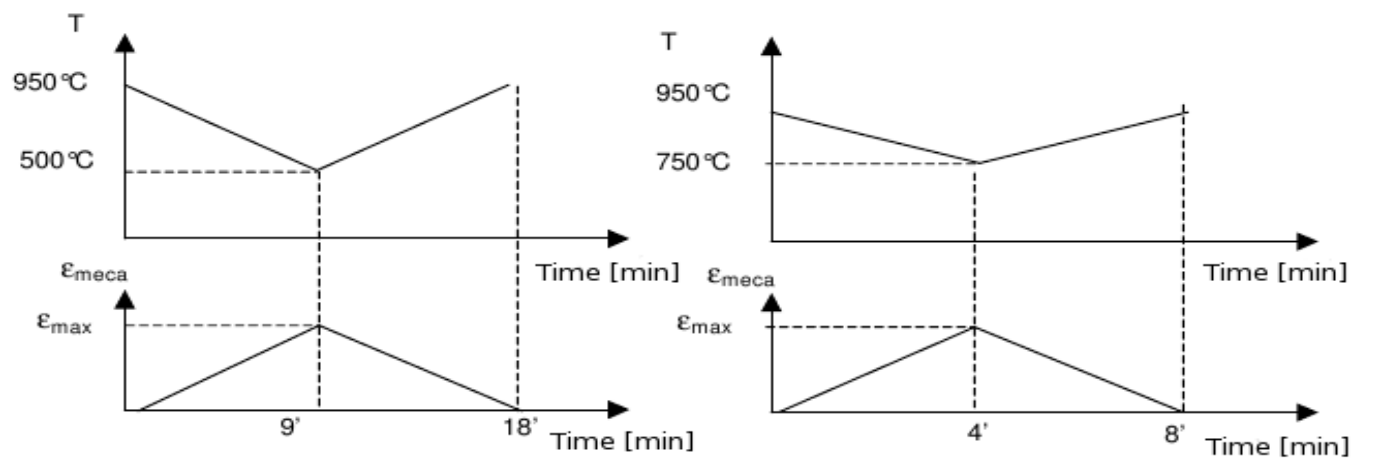

$\underline{\text { Cycle } 1}$

$\underline{\text { Cycle } 2}$
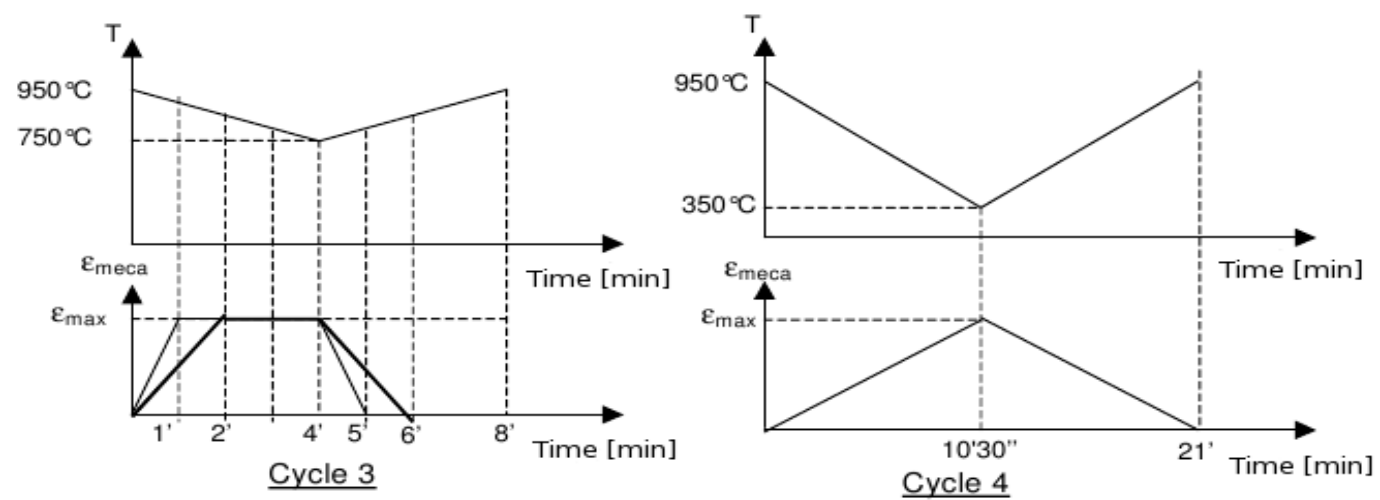

Fig. 5: Non-isothermal cycles considered for Thermo-mechanical model validation tests

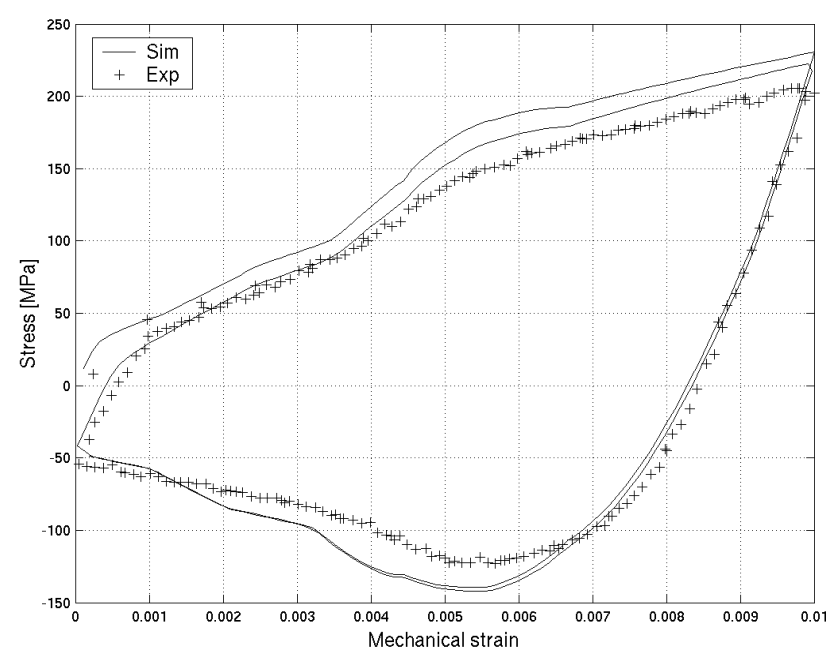

(a)

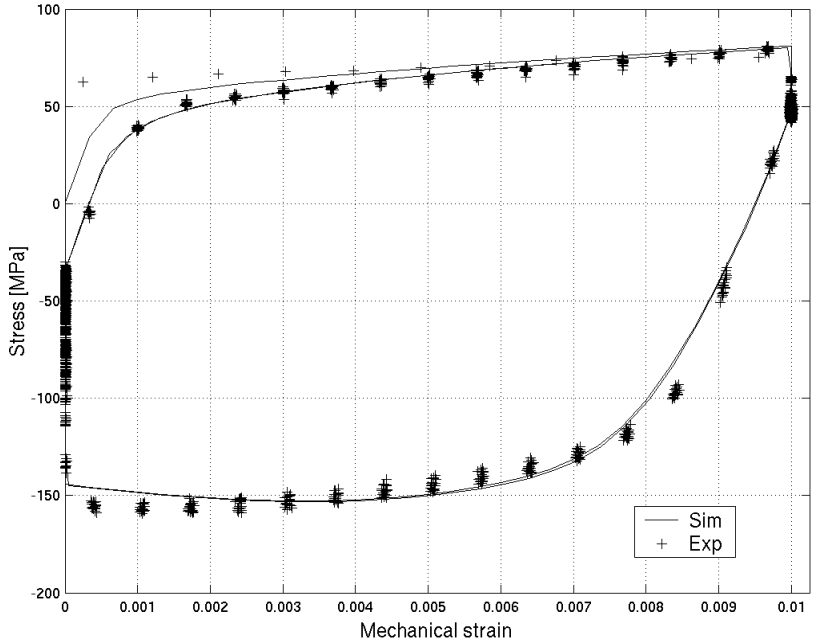

(b)

Fig. 6: Thermo-mechanical fatigue tests for the GX30NiCr39-24 steel (a) cycle 1 with a mechanical strain of $1 \%$ (b) cycle 3 with a mechanical strain of $1 \%$ and a dwell time of 3 min 
This validation was only conducted on GX30NiCr39-24 steel. Fig. 6 shows some predictions of the behaviour model in thermo-mechanical conditions for cycle 1, with a mechanical strain range of $1 \%$, and for cycle 3 with a tensile dwell time of 3 minutes. Same agreements are obtained for the other thermo-mechanical fatigue tests [9].

Fatigue Lifetime Investigation of GX30NiCr39-24 Heat Resistant Steel. An experimental isothermal fatigue program was conducted on GX30NiCr39-24 steel, in order to investigate its lifetime. Strain controlled tests were performed with a larger gauge length $(25 \mathrm{~mm})$, in order to reduce grain size effects. Heating was achieved with a resistive furnace with a temperature range between 20 and $920^{\circ} \mathrm{C}$, a mean constant strain rate of $10^{-3} \mathrm{~s}^{-1}$ and several strain amplitudes between \pm 0.2 and $\pm 0.7 \%$. Fig. 7 illustrates the lifetime fatigue tests.

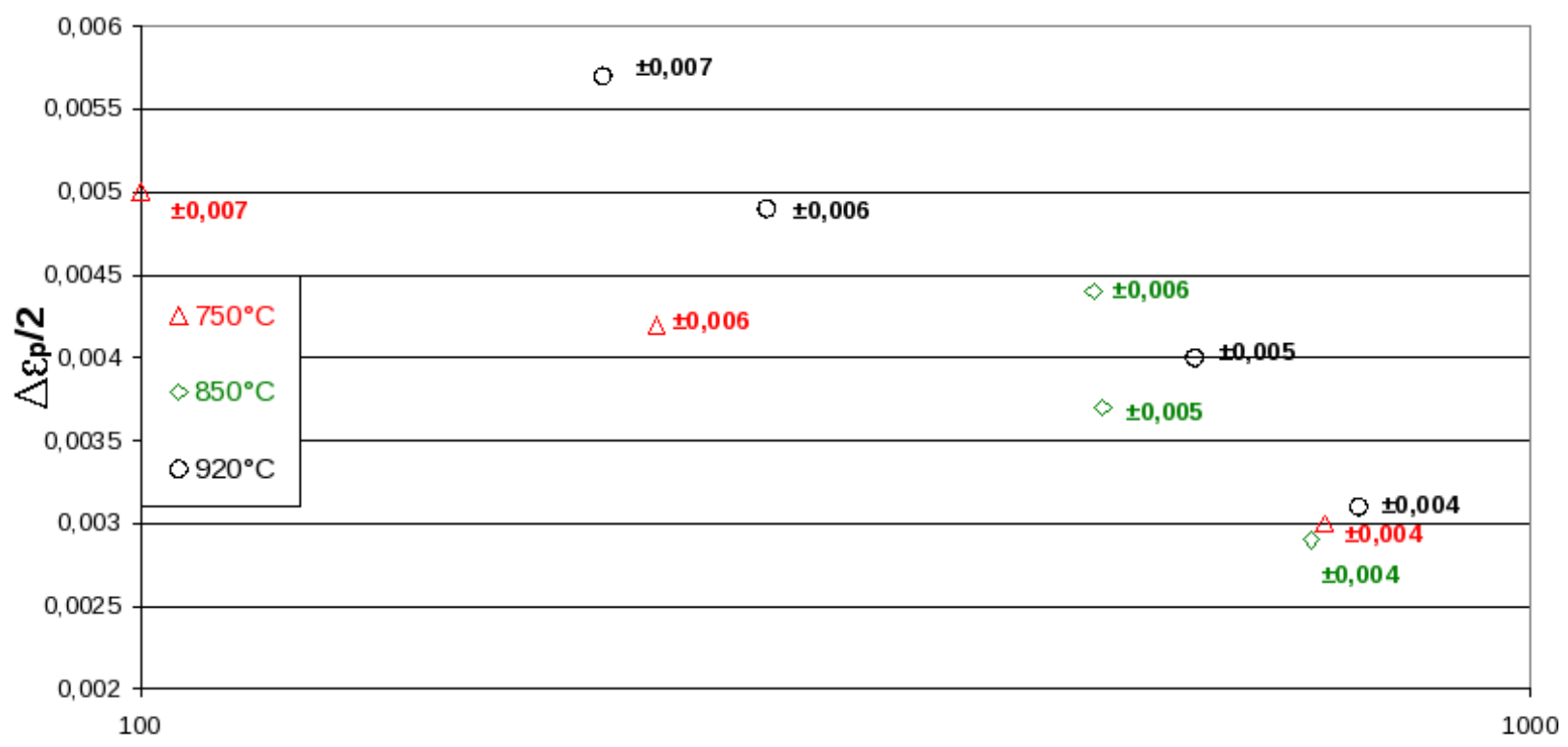

Number of Cycles

Fig. 7: Lifetime fatigue results performed on GX30NiCr39-24 steel

For each of them, the mid-life parameters (strain and stress amplitudes) and the number of cycles to failure $\mathrm{N}_{R}$ are reported. Fatigue lifetime is greatly influenced by the temperature levels. Indeed, for the same applied strain range, a stress amplitude factor reduction of 3 is observed between 20 and $920^{\circ} \mathrm{C}$. Very short lifetimes are obtained at $20^{\circ} \mathrm{C}$; then they increase with temperature to reach a maximal lifetime at $500^{\circ} \mathrm{C}$. Afterwards, lifetimes decrease again but remain more important than those provided at $20^{\circ} \mathrm{C}$. Last, lifetimes slightly increase with temperature from 750 to $920^{\circ} \mathrm{C}$. Fig. 8 illustrates this phenomenon for a strain range of $\Delta \varepsilon= \pm 0.4 \%$.

In order to investigate the damage mechanisms, SEM (Scanning Electron Microscope) observations were performed on post mortem samples and through in-situ tensile test at room temperature. Micro-structural investigations show a crack initiation located to the chromium primary carbides $\left(\mathrm{M}_{23} \mathrm{C}_{6}\right)$ and propagation along the inter-dentritic carbide network around the austenitic grains. Moreover, beside crack initiation which occurs at the surface of the specimen, internal cracks were also observed within the sample. This phenomenon is not dependent on the test temperature and it corresponds to an inter-granular failure mechanism. The in-situ SEM observations during a tensile test confirm the results provided by post mortem analysis. Fig. 9 shows an in-situ SEM observation of the tensile test. The crack initiation is only located along the eutectic carbides. 


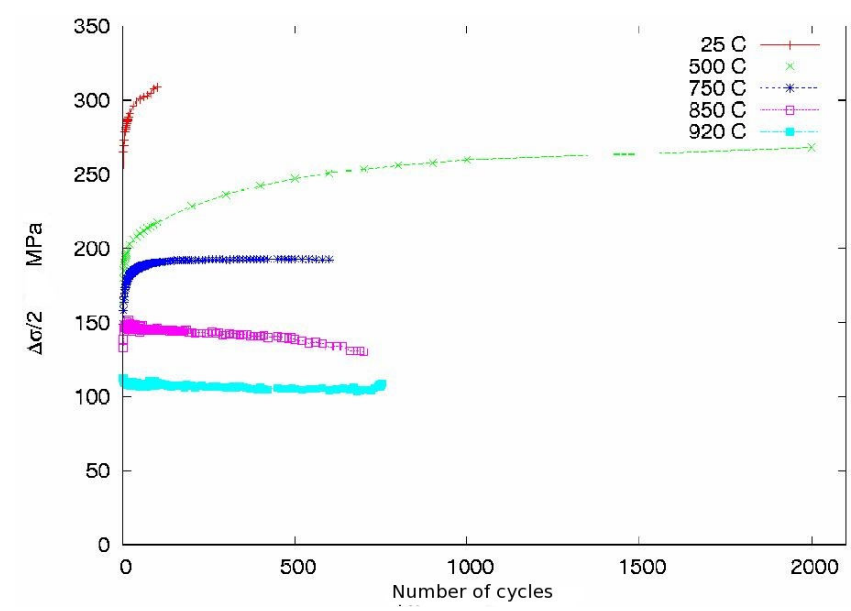

Fig. 8: Evolution of the stress amplitude versus the number of cycles for an applied strain of $\pm 0.4 \%$.

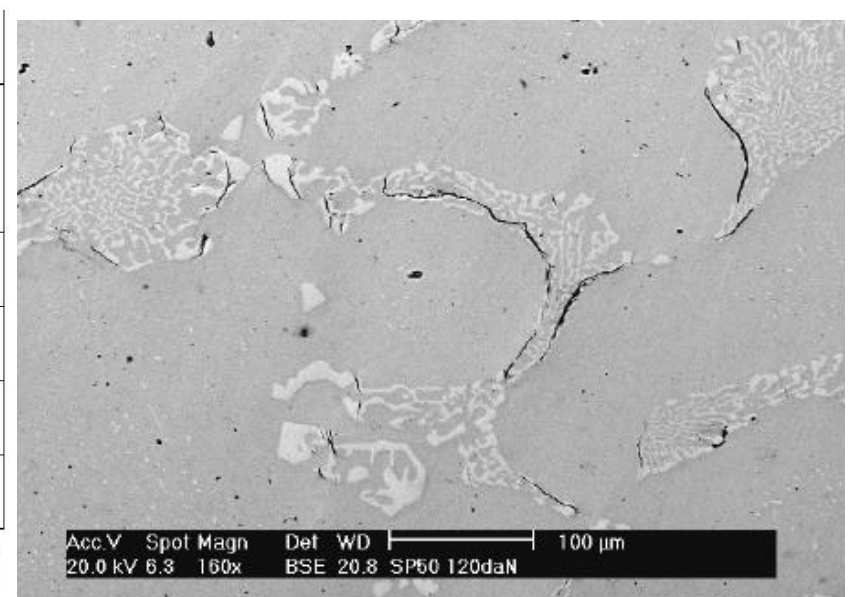

Fig. 9: In-situ SEM observation (tensile test performed at room temperature).

\section{Conclusion}

The fatigue behaviour and lifetime of both heat resistant steels commonly used to manufacture SPF dies were investigated. First, an experimental methodology was presented to identify the parameters of a constitutive behaviour model. This approach allows describing typical loadings close to those induced in the industrial mould such as strain rate effect or stress relaxation during tensile dwell time. It was successfully applied for isothermal and non-isothermal conditions. Then, a lifetime investigation was performed to understand the damage mechanisms occurring on the GX30NiCr3924 steel. It considers post-mortem observations from isothermal fatigue tests at different temperatures and in-situ SEM tensile tests. Both analyses show an inter-granular crack initiation along the primary carbides, regardless of the test conditions (temperature, strain rate...).

\section{References}

[1] T. Branza, A. Martinier, A. Duchosal, F. Deschaux-Beaume, G. Bernhart and P. Lours: Proceedings of EuroSPF 2004 Conference, Ecole Mines, Albi, France (2004), p.133.

[2] S. Baleix, G. Bernhart and P. Lours: Material Science Engineering A 327 (2004), p. 139.

[3] G. Luckey, P. Friedman and K. Weinmann: Journal of Materials, Processing and Technology 209/4 (2009), p. 2152.

[4] A.A. Deshpande, S.B. Leen and T.H. Hyde: Proceedings of the EuroSPF 2008, Toulouse University, Mines Albi, France (2008). http://hal.archives-ouvertes.fr/EUROSPF2008/en/.

[5] V. Velay, T. Cutard and N. Guegan: Proceedings of the EuroSPF 2008, Toulouse University, Mines Albi, France (2008). http://hal.archives-ouvertes.fr/EUROSPF2008/en/.

[6] T. Branza, F. Deschaux-Beaume, V. Velay and P. Lours: Journal of Materials Processing and Technology 209 (2009), p. 944.

[7] V. Velay, D. Delagnes and G. Bernhart: Key Engineering Materials 378-379 (2008), p. 81.

[8] J. Lemaître and J-L. Chaboche: Mechanics of Solid Materials (Cambridge University Press, UK 1994).

[9] A. Martinier: Ph.D. Thesis, Ecole des Mines de Paris- ENSMP (2005). 